(1)

CrossMark

\title{
Chronic breathlessness: time for Cinderella to go to the ball!
}

\author{
Miriam J. Johnson ${ }^{1}$ and Marie Fallon ${ }^{2}$ \\ Affiliations: ${ }^{1}$ Wolfson Palliative Care Research Centre, Hull York Medical School, University of Hull, Hull, UK. \\ ${ }^{2}$ Institute of Genetics and Molecular Medicine, Edinburgh Cancer Research Centre, University of Edinburgh, \\ Edinburgh, UK.
}

Correspondence: Miriam J. Johnson, Wolfson Palliative Care Research Centre, Hull York Medical School, University of Hull, Hull, HU6 7RX, UK. E-mail: miriam.johnsonahyms.ac.uk

@ERSpublications

If clinicians do not recognise chronic breathlessness as something serious which warrants further intervention and for which interventions are available, much suffering which could be ameliorated will remain hidden http://ow.ly/KP7b30lpzey

Cite this article as: Johnson MJ, Fallon M. Chronic breathlessness: time for Cinderella to go to the ball! Eur Respir J 2018; 52: 1801452 [https://doi.org/10.1183/13993003.01452-2018].

Breathlessness is a peculiar issue. The normal physiological response to exertion (physical or emotional) is clearly not a "symptom", defined as a physical or mental manifestation of disease apparent to the patient (English Oxford Living Dictionary). However, breathlessness is also one of the most common, serious and distressing symptoms caused by disease(s). Perhaps these extremes explain partly why the change from "normal" to "symptom" is often unrecognised by the breathless patient, their family and friends and their healthcare professionals, particularly when this shift occurs insidiously [1]. It may also reduce the legitimacy of breathlessness as a reason to seek medical help until the symptom has become a visible and objectively measurable clinical sign of respiratory difficulty [2]. Additional barriers include misattribution of breathlessness solely to physiological deconditioning or growing older [1], or the fear of censure and stigma associated with smoking [3] or being overweight. Too often, the patient presents only when serious limitations affecting work, finances, family role and social interaction have accrued, when the breathlessness provokes an anxious emotional response that can no longer be ignored, or in crisis needing immediate medical intervention.

If patients do seek medical help they can appear comfortable at rest and the subjective symptom, unmeasurable with a simple "test" [4], correlates poorly with objective measures of pulmonary function. Consequently symptom severity and impact is not usually assessed systematically and is rarely addressed as anything other than a signpost to medical disease. Breathlessness persisting despite optimal treatment of any diagnosed disease slips back into "normal", expected by patient, family and healthcare professional, but with no expectation that this Cinderella should be seen outside of the kitchen hearth, if at all. This nihilistic approach is fed by a number of factors related to patients, clinicians or institutional processes and structures. Firstly, patients often believe that it is their responsibility to manage (or simply avoid by less and less physical activity) [1]. Associated with this is the lack of any patient lobby, which reflects the general lack of information about what could be possible in breathlessness management. Secondly, healthcare professionals may believe that nothing can be done anyway; we are very good at not seeing problems we think we cannot fix. Thirdly, if healthcare professionals do have an understanding of the widespread impact of chronic breathlessness on quality of life and they are aware of breathlessness interventions, they may be concerned about the time pressures restricting holistic assessment, may have 
poor access to non-pharmacological interventions, especially psychological, and have concerns about prescribing opioids [5].

Ahmadi et al. [6], in this issue of the European Respiratory Journal, present hard-hitting evidence. Primary and secondary care physicians were asked to complete a survey based around a case scenario of a patient with severe COPD "troubled by severe [breathlessness or pain; randomly allocated] that markedly restricted daily activities and that had remained unchanged for at least 3 months". They showed that compared to chronic pain of similar severity, fewer physicians recognised the need for further intervention ( $10 \%$ breathlessness versus $31 \%$ pain), fewer offered symptom-directed treatments ( $4 \%$ versus $24 \%$ ) with a similarly small minority offering opioids (3\% versus $23 \%$ ). Given the severe and disabling nature of the symptom described, it is disturbing to see that only a third of physicians recognised the need for further interventions for pain. Even more worrying is the stark finding that only a tenth saw the need for further intervention for breathlessness with less than one in 20 suggesting specific breathlessness treatments. Even though we may cling to the hope that this scenario-based exercise may not accurately reflect clinical practice, the findings will have a face validity for many.

The tragedy is that evidence-based interventions are available [7-10], but even the best known, such as pulmonary rehabilitation, are poorly implemented and underused. Even if referred, breathlessness is a common reason for patients not attending or not completing rehabilitation; many patients are unaware that exertion-induced breathlessness of itself is not harmful. Few are given strategies to manage exertion-induced breathlessness to enable adequate engagement with exercise-based programmes. Although breathlessness management clinics $[8,11]$ are still relatively uncommon, self-management techniques are often known to respiratory and palliative care clinicians (hand-held fan [9, 12, 13], breathing training, pacing/prioritising, relaxation and other cognitive techniques [14]) and can be incorporated in routine practice. Time spent assessing the impact of, and the way patients cope with and seek help for, breathlessness leading to tailored interventions [15] will be time well spent if these improve patient and family quality of life, experiences and reduce health service use $[16,17]$.

Over the past decade there has been a welcome and increasing focus on breathlessness as an important symptom to be managed alongside the diagnostic and treatment pathway [18] and on chronic breathlessness as a defined entity and therapeutic target [19]. Assessment and management of disease, its complications and symptoms should continue throughout the disease trajectory with attention to complications and symptoms taking primary place once optimum tolerated treatment is reached [2].

There are now useful frameworks to guide assessment and treatment $[15,18,20]$, but 10 years after the seminal paper describing the invisibility of breathlessness in people with COPD [1], we do not appear to be much further in clinical practice [21]. The aim of defining chronic breathlessness [19] is to legitimise patient presentation to healthcare professionals, to encourage healthcare professionals to assess chronic breathlessness routinely, to give leverage to improve access to breathlessness services/interventions and to stimulate further research into the mechanisms and management of this still neglected symptom.

30 years ago, similar concerns were raised about chronic pain and still raise their head [22]. Accessibility of pain services and research have all increased, albeit variably with regard to implementation and provision, and a strong chronic pain patient lobby exists. A recent large randomised controlled trial of education and training in chronic cancer pain assessment and management, based on a simple but precise pain intensity measurement, has demonstrated clearly the marked improvements in pain relief without adverse effects which are possible for non-specialists [23]. The pace of adoption of routine pain assessment and management beyond pain or palliative specialists is clearly slow; still only one third of physicians recognised the need for further interventions for pain. That lack of recognition is of course based on complex medical and human phenomena.

In chronic breathlessness, we have the advantage of following in the footsteps of chronic pain, and can identify pitfalls to avoid or at least mitigate against. As patients may live for many months or years with chronic breathlessness, fear of opioid misuse is a legitimate concern. However, a dose titration study of extended release morphine for breathlessness showed that over half of responders did so by $10 \mathrm{mg}$ per $24 \mathrm{~h}$ and over $90 \%$ by $20 \mathrm{mg}$ per $24 \mathrm{~h}$ [24]; doses not associated with excess mortality or hospital admission in 4 years' follow-up of people with severe COPD [25]. These are doses markedly lower than those associated with psychological dependence and misuse; issues in relation to opioids for pain should not be automatically assumed for breathlessness [26]. The misuse potential is lower with extended release preparations compared with immediate release [27] and for morphine compared with other oral opioids [28]. Given that the best evidence for breathlessness is for extended release morphine [29] and largest effect size is for steady state [30], this would support the use of extended release preparations rather than immediate release on counts of both effectiveness and misuse potential. 
Fear of opioid-related adverse events, and of respiratory depression in particular, is a significant educational challenge as this is unfounded when prescribed and titrated appropriately for breathlessness [31]. Interestingly, in the randomised trial reported by AHMADI et al. [6], compared with prescription for pain, physicians expressed a greater lack of knowledge and confidence about the appropriate opioid regimen, whereas concerns about adverse events were similar between prescription for pain or breathlessness. Education and training for physicians prescribing morphine for breathlessness is therefore important to ensure the right drug, with the optimum preparation, dose and dosing schedule, with the appropriate safety monitoring is practised. In this way, adverse event rates should mirror more closely those seen in randomised controlled trials.

We must also learn from the field of chronic pain in recognising the importance of a multi-disciplinary approach; opioid prescription is only considered in those already receiving non-pharmacological treatments in the context of attention to lifestyle and self-management [32]. This is an important message to health service providers and service funders/commissioners; there must be adequate provision of physio- and occupational therapists, of psychologists and cognitive behavioural therapists and a service configuration which allows systematic assessment of the impact of chronic breathlessness on the individual and their family. In addition, education and support for family members is important [33]; recent work indicates that, as with pain, breathlessness can be vicariously experienced by empathetic observers [34].

Meanwhile, how can we help patients to recognise that chronic breathlessness is a legitimate and an important issue to bring to clinical attention? If their clinicians do not recognise chronic breathlessness as something serious and affecting a basic human right $[35,36]$, which warrants further intervention and for which interventions are available, much suffering which could be ameliorated will remain hidden.

Cinderella must go to the ball, but how can she go without an invitation?

Conflict of interest: M.J. Johnson received institutional payments as clinical advisor to Mayne Pharma, outside the submitted work. M. Fallon has nothing to disclose.

\section{References}

1 Gysels M, Higginson IJ. Access to services for patients with chronic obstructive pulmonary disease: the invisibility of breathlessness. J Pain Symptom Manage 2008; 36: 451-460.

2 Johnson MJ, Currow DC, Booth S. Prevalence and assessment of breathlessness in the clinical setting. Expert Rev Respir Med 2014; 8: 151-161.

3 Tod AM, Joanne R. Overcoming delay in the diagnosis of lung cancer: a qualitative study. Nurs Stand 2010; 24: 35-43.

4 Carel H. Breathlessness: the rift between objective measurement and subjective experience. Lancet Respir Med 2018; 6: 332-333.

5 Young J, Simpson C, Farquhar M, et al. Attitudes to using opioids to treat dyspnea in advanced COPD: a qualitative study of family physicians and respiratory therapists. Chest 2009; 136: 91S.

6 Ahmadi Z, Sandberg J, Shannon-Honson A, et al. Is chronic breathlessness less recognised and treated compared with chronic pain? A case-based randomised controlled trial. Eur Respir J 2018; 52: 1800887.

7 Ekstrom M, Bajwah S, Bland JM, et al. One evidence base; three stories: do opioids relieve chronic breathlessness? Thorax 2018; 73: 88-90.

8 Higginson IJ, Bausewein C, Reilly CC, et al. An integrated palliative and respiratory care service for patients with advanced disease and refractory breathlessness: a randomised controlled trial. Lancet Respir Med 2014; 2: 979-987.

9 Luckett T, Phillips J, Johnson MJ, et al. Contributions of a hand-held fan to self-management of chronic breathlessness. Eur Respir J 2017; 50: 1700262.

10 McCarthy B, Casey D, Devane D, et al. Pulmonary rehabilitation for chronic obstructive pulmonary disease. Cochrane Database Syst Rev 2015: CD003793.

11 Farquhar MC, Prevost A, McCrone P, et al. Is a specialist breathlessness service more effective and cost-effective for patients with advanced cancer and their carers than standard care? Findings of a mixed-method randomised controlled trial. BMC Med 2014; 12: 194.

12 Galbraith S, Fagan P, Perkins P, et al. Does the use of a handheld fan improve chronic dyspnea? A randomized, controlled, crossover trial. J Pain Symptom Manage 2010; 39: 831-838.

13 Johnson MJ, Booth S, Currow DC, et al. A mixed-methods, randomized, controlled feasibility trial to inform the design of a phase III trial to test the effect of the handheld fan on physical activity and carer anxiety in patients with refractory breathlessness. J Pain Symptom Manage 2016; 51: 807-815.

14 Livermore N, Dimitri A, Sharpe L, et al. Cognitive behaviour therapy reduces dyspnoea ratings in patients with chronic obstructive pulmonary disease (COPD). Respir Physiol Neurobiol 2015; 216: 35-42.

15 Hutchinson A, Barclay-Klingle N, Galvin K, et al. Living with breathlessness: a systematic literature review and qualitative synthesis. Eur Respir J 2018; 51: 1701477.

16 Currow DC, Clark K, Mitchell GK, et al. Prospectively collected characteristics of adult patients, their consultations and outcomes as they report breathlessness when presenting to general practice in Australia. PLoS One 2013; 8: e74814

17 Hutchinson A, Pickering A, Williams P, et al. Breathlessness and presentation to the emergency department: a survey and clinical record review. BMC Pulm Med 2017; 17: 53.

18 Hopkinson NS, Baxter N. Breathing SPACE-a practical approach to the breathless patient. NPJ Prim Care Respir Med 2017; 27: 5 . 
19 Johnson MJ, Yorke J, Hansen-Flaschen J, et al. Towards an expert consensus to delineate a clinical syndrome of chronic breathlessness. Eur Respir J 2017; 49: 1602277.

20 Spathis A, Booth S, Moffat C, et al. The Breathing, Thinking, Functioning clinical model: a proposal to facilitate evidence-based breathlessness management in chronic respiratory disease. NPJ Prim Care Respir Med 2017; $27: 27$.

21 Carel H, Macnaughton J, Dodd J. Invisible suffering: breathlessness in and beyond the clinic. Lancet Respir Med 2015; 3: 278-279.

22 Addison RG. Chronic pain syndrome. Am J Med 1984; 77: 54-58.

23 Fallon M, Walker J, Colvin L, et al. Pain management in cancer center inpatients: a cluster randomized trial to evaluate a systematic integrated approach - the Edinburgh Pain Assessment and Management Tool. J Clin Oncol 2018; 36: 1284-1290.

24 Currow DC, McDonald C, Oaten S, et al. Once-daily opioids for chronic dyspnea: a dose increment and pharmacovigilance study. J Pain Symptom Manage 2011; 42: 388-399.

25 Ekstrom MP, Bornefalk-Hermansson A, Abernethy AP, et al. Safety of benzodiazepines and opioids in very severe respiratory disease: national prospective study. BMJ 2014; 348: g445.

26 Verberkt CA, van den Beuken-van Everdingen MHJ, Schols JMGA, et al. Adverse respiratory effects of opioids for chronic breathlessness: to what extent can we learn lessons from chronic pain? Eur Respir J 2018; 52: 1800882.

27 Cicero TJ, Ellis MS, Kasper ZA. Relative preferences in the abuse of immediate-release versus extended-release opioids in a sample of treatment-seeking opioid abusers. Pharmacoepidemiol Drug Saf 2017; 26: 56-62.

28 Coplan PM, Sessler NE, Harikrishnan V, et al. Comparison of abuse, suspected suicidal intent, and fatalities related to the 7-day buprenorphine transdermal patch versus other opioid analgesics in the National Poison Data System. Postgrad Med 2017; 129: 55-61.

29 Abernethy AP, Currow DC, Frith P, et al. Randomised, double blind, placebo controlled crossover trial of sustained release morphine for the management of refractory dyspnoea. BMJ 2003; 327: 523-528.

30 Ekstrom M, Nilsson F, Abernethy AA, et al. Effects of opioids on breathlessness and exercise capacity in chronic obstructive pulmonary disease. A systematic review. Ann Am Thorac Soc 2015; 12: 1079-1092.

31 Verberkt CA, van den Beuken-van Everdingen MHJ, Schols JMGA, et al. Respiratory adverse effects of opioids for breathlessness: a systematic review and meta-analysis. Eur Respir J 2017; 50: 1701153.

32 Marciniuk DD, Goodridge D, Hernandez P, et al. Managing dyspnea in patients with advanced chronic obstructive pulmonary disease: a Canadian Thoracic Society clinical practice guideline. Can Respir J 2011; 18: 69-78.

33 Farquhar M, Penfold C, Benson J, et al. Six key topics informal carers of patients with breathlessness in advanced disease want to learn about and why: MRC phase I study to inform an educational intervention. PLoS One 2017; 12: e0177081.

34 Herzog M, Sucec J, Van Diest I, et al. Observing dyspnoea in others elicits dyspnoea, negative affect and brain responses. Eur Respir J 2018; 51: 1702682.

35 Currow DC, Abernethy AP, Ko DN. The active identification and management of chronic refractory breathlessness is a human right. Thorax 2014; 69: 393-394.

36 Basoglu M. Effective management of breathlessness: a review of potential human rights issues. Eur Respir J 2017; 49: 1602099 . 